\title{
Distribution patterns of macrofaunal species diversity in subtidal soft sediments: biodiversity-productivity relationships from the MacroBen database
}

\author{
V. Escaravage ${ }^{1, *}$, P. M. J. Herman, B. Merckx, M. Włodarska-Kowalczuk, J. M. Amouroux, \\ S. Degraer, A. Grémare, C. H. R. Heip, H. Hummel, I. Karakassis, C. Labrune, W. Willems
}

${ }^{1}$ Netherlands Institute of Ecology, Center for Estuarine and Marine Ecology, Monitor Taskforce, PO Box 140, 4400 AC Yerseke, The Netherlands

\begin{abstract}
We analyzed patterns of species diversity in a compiled data set covering the European coast (from Norway to Crete) that was made available in the framework of the MarBEF European Network of Excellence. The focus was on the distribution patterns of species diversity over large areas across Europe. The objectives of our analysis were two-fold. First, we attempted to separate the effects of species-area relationships from that of species accumulation. Second, we explored the relationship between species diversity and productivity, and compared this to the proposed explaining factors (depth, survey area and latitude). The following conclusions are drawn. (1) Within a given habitat (subtidal soft sediment), the distribution of marine macrofaunal species richness in different areas between 3 and $200 \mathrm{~m}$ in average depth throughout Europe is shown to follow general rules derived from observations and experiments mostly based on terrestrial communities; (2) soft-bottom macrofauna accumulate in the subtidal environment (up to $200 \mathrm{~m}$ ) following the Arrhenius plot model at a rate $(\approx 0.5)$ corresponding to about a 3 -fold increase in the number of species when the sampling area increases by 1 order of magnitude; (3) the distribution of the intrinsic species richness (point species richness) between the selected data sets (subtidal soft sediment) is significantly correlated with the levels of organic flux reaching the sea bottom; and (4) the close relationship between depth and the fraction of surface primary production that reaches the sea bottom is proposed as an explanation for the previously described increase of species richness with depth.
\end{abstract}

KEY WORDS: Species-area relationship $\cdot$ Species accumulation curve $\cdot$ Macrobenthos $\cdot$ Species richness $\cdot$ Productivity

\section{INTRODUCTION}

International agreements (e.g. EU Marine Strategy) require signatory nations to make inventories of biodiversity, monitor changes and mitigate negative effects of human activities on biodiversity. Logistics, however, often prevent the direct census of species at large spatial scales. On the other hand, the observed species richness could seriously underestimate the actual species richness due to undersampling of rare species (Gray et al. 2005). This is particularly true for soft-bottom macrofauna (sediment-dwelling metazoans retained by a $1 \mathrm{~mm}$ sieve), where individual sampling areas of at most $1 \mathrm{~m}^{2}$ are used to describe species richness for areas that are usually about 6 orders of magnitude larger $\left(\mathrm{km}^{2}\right)$. Therefore, an accurate description of biodiversity and changes therein requires a proper understanding of the spatial patterns and driving factors of species diversity.

Historical and present views on marine biodiversity have recently been depicted by Gray $(1997,2000,2001$, 2002). These studies emphasize the main drivers of species diversity patterns. In addition, they define different scales of observation at which biodiversity might be considered, along with biological organization scaling from genes to ecosystems and through spatial scales from habitats to landscapes and biogeographical provinces. 
Based on the work published by Sanders (1968), 2 main paradigms in benthic macrofaunal species diversity patterns have been identified: (1) a positive cline from the poles to the tropics and (2) an increase with depth from shallow waters to a maximum just seaward of the continental rise followed by a decrease thereafter (Levinton 1995). Gray (2001) reviewed these patterns and acknowledged a cline in increasing species richness from the Arctic to the tropics and the surprisingly high species richness in deep-sea areas. The high diversity in the deep sea might be explained, following Gray et al. (1997), at least partly by the vast area surveyed by oceanographers in this kind of environment in comparison to coastal areas. Besides the latitudinal cline, 2 key factors may explain patterns of marine macrofaunal species diversity: habitat heterogeneity and surveyed area (Gray 2001). Furthermore, Gray (2002) identified the available food resources as a limiting factor for the maximum range of species. As a consequence, where point species richness (at the scale of sampling stations) is concerned for similar habitats (e.g. soft bottom in the present study), latitude, depth, surveyed area and productivity could then be expected to be responsible for the observed patterns.

It is generally known that species diversity in natural systems can strongly depend on productivity as predicted with the energy hypothesis by Wright (1983), who interprets the difference in species-area relationships between the polar regions, with low (solar) energy input, and the tropics. Marine sediments, with the exception of very shallow and intertidal sites where primary production by microphytobenthos can be important, receive most their energy input from the pelagic system and this input is strongly depthdependent (Andersson et al. 2004). The decreased food input as a function of depth was furthermore proposed by Rex \& Etter (1998) as an explanation for the decrease in gastropod species richness from coast to abyss in the North Atlantic.

Mostly unimodal (i.e. humped) relationships between species richness and measures of ecosystem productivity have been described (Rex 1981, Rosenzweig \& Abramsky 1993, Tilman \& Pacala 1993, Hall et al. 2000). The diversity-productivity (D-P) hypothesis states that there is a corresponding increase in species richness as productivity increases, until a point where additional productivity results in lower species richness (Connell \& Orias 1964). This hypothesis is in oppositon, however, to a number of model predictions of a monotonic D-P relationship, a fact which is interpreted by Rosenzweig $(1992,1995)$ and Leibold (1999) as a difference in spatiotemporal scale: monotonic curves represent a transient response to (mostly experimental) increases in resources whereas unimodal patterns are established in the longer term under quasi-steady state conditions.
The part of the unimodal curve where species richness decreases for increasing productivity corresponds to the so called paradox of enrichment (Rosenzweig 1971) that describes an inverse relationship between productivity and diversity.

For benthic systems, Levin et al. (2001) provided an extensive overview of the possible influence of productivity on diversity in the deep sea. They show that diverse relationships (increasing, decreasing and humped) are found, but also point out that these are not necessarily contradictory. In general, ascending relations between productivity and diversity are described from very oligotrophic areas, whereas the reverse is true in more eutrophic areas and humped curves are described for broader ranges of productivity (Levin et al. 2001).

Leibold (1999) compared the patterns of 4 welldeveloped models predicting unimodal D-P relationships (paradox of enrichment, resource heterogeneity hypothesis, resource-ratio hypothesis and the keystone predation hypothesis) with those observed in fishless ponds in Michigan, USA, between the nutrient levels and the density, diversity and composition of plants (phytoplankton) and herbivores (zooplankton). The observed changes in the patterns of distribution of planktonic organisms were consistent with the keystone predation hypothesis, where species richness results from the balance between resource competition and differential grazing pressure by shared predators. At low productivity levels, and when predators are rare, the community is dominated by a few efficient exploiters (mostly vulnerable for predation) who might coexist with poorer resource exploiters (mostly predation resistant) when productivity increases. This agrees with the findings of Gross \& Cardinale (2007) from metacommunity models where humped D-P curves were observed in communities that are structured by resource competition because species are able to coexist only via niche partitioning at intermediate levels of resource supply. Experimental nutrient enrichment experiments by Hall et al. (2000) also suggested the unimodal form of the D-P relationship by macrofauna, which contradicts the resource heterogeneity hypothesis as a monotonic increase of algal diversity with the nutrient enrichment.

The species-area hypothesis is one of the general principles in ecology that describes an increase in the number of species found with surveyed area (Rosenzweig 1995). As pertinently noticed by Gray (2001), the species-area relationship should not be confused with the species accumulation curve that describes how the number of species increases with the area and/or number of samples taken in a given environment. Rosenzweig (1995) explained the increasing number of species with area as due to the space and/or niche requirements, with generally higher habitat diversity 
and higher numbers of individuals in large than small areas. In contrast with the terrestrial environment, few marine data have been used to test this hypothesis. This hypothesis is particularly difficult to test using data sets on benthic macrofauna, since all data have been collected in point samples of small area, not by area-covering surveys. These point samples may be spread uniformly or randomly over the surveyed area. When looking at total number of species sampled when accumulating $1,2 \ldots \mathrm{n}$ samples within a data set, inevitably the total surveyed area (i.e. the domain in which the samples have been taken) increases concomitantly with the total area sampled (i.e. the summed area of all box or grab cores taken). Tearing apart the 2 aspects is not a trivial task and requires insight into the spatial organization of species diversity.

In the present study we analyzed patterns of species diversity in a compiled data set covering the European coast. The issues investigated by our analysis were: (1) the respective effects of species-area relationships and of species accumulation on the assessment of species diversity, and (2) the shape of the relationship between species diversity and productivity follows the unimodal pattern. We also explored the environmental factors (depth, survey area and latitude) which may affect the aforementioned D-P relationship.

\section{MATERIALS AND METHODS}

Macrofaunal diversity data set. We used the MacroBen database, developed within the MarBEF Network of Excellence (Vanden Berghe et al. 2009, this Theme Section). Depth values are available for 385150 distribution records (86\%) which are distributed over a geographical area between $30-80^{\circ} \mathrm{N}$ in latitude and $30^{\circ} \mathrm{E}$ to $30^{\circ} \mathrm{W}$ in longitude. Nevertheless, the samples are not evenly distributed over the zone covered by the data as a result of highly variable sampling intensities (Fig. 1).

The sampling points are identified by their geographical location together with the date and the data set they belong to. A data set represents here a group of records that was delivered by a data provider to the MarBEF project. The sampling and analytical procedures within a given dataset are generally homogeneous.

In order to standardize the data extracted from the database (Microsoft Visual Basic for Applications), routines have been made available by the Flanders Marine Institute (VLIZ) that control the extraction of the data according to criteria about the data sets to be used, required level of taxonomic identification, spatial-temporal lumping and a cut-off for rare species when required. Other routines allow standard operations such as export data, preliminary analysis, calculation of indices and calculation of grid cells.
An effort to limit the data heterogeneity was attempted through preliminary filtering by selecting for each data set the years where at least 20 sampling stations were visited. A total of 78 distinct combinations of dataset $\times$ year complying with this criterion were selected, and 25 distinct geographical groups with no more than 1 data set per group were thus identified. A final selection was made of the data sets with taxonomic identifications to the species level with the subselect routine that is provided along with the database. This selection retained data sets representing 15 geographical groups (A to O) with a total of 93860 distribution records, 5888 sampling records and 2584 species. Each record contains the species name, number of counted individuals and corresponding sampling surface.

Data processing. Two different approaches were used to establish species accumulation curves (i.e. curves representing how the total number of species sampled increases with total area of the samples). In the gridded approach, species were accumulated in samples that are geographically as close to each other as possible. The total area surveyed by a group of $n$ samples thus increases with increasing sample number. In the randomization approach, the total area surveyed is always equal to the maximum area (total span of the data set), and samples are accumulated by random selection from the total set. We consider these approaches as the extremes in establishing species accumulation curves.

For the gridded approach, we subdivided the total area sampled by a dataset into a grid, so that, on average, every grid cell contained 1 sample. Subsequently, coarser grids were constructed from the basic grid by lumping neighbouring cells. Thus, the final set of grids was designed such that grid cells respectively contained, on average, 1, 2, 4, 8 ... 1024 sampling points. For each of these grids, the average number of species found per cell was plotted against the corresponding average sampling surface per cell.

For the randomization approach, we accumulated (without replacement) 1, 2, 4, 8 .. 1024 randomly chosen samples from the total data set without consideration of their geographical position, and repeated this procedure 1000 times. The average number of species found in the 1000 draws of 1, 2, 4, 8 .. 1024 samples was plotted against the average sampling surface.

Both approaches were compared with respect to the parameters of the species accumulation curves fitted to the data. For this comparison, the Arrhenius (log-log) plot model was selected (see 'Discussion'):

$$
\log (S)=z \log (A)+\log (C)
$$

where $S$ is the average number of species observed at a given average sampling surface area $A, z$ is the rate 


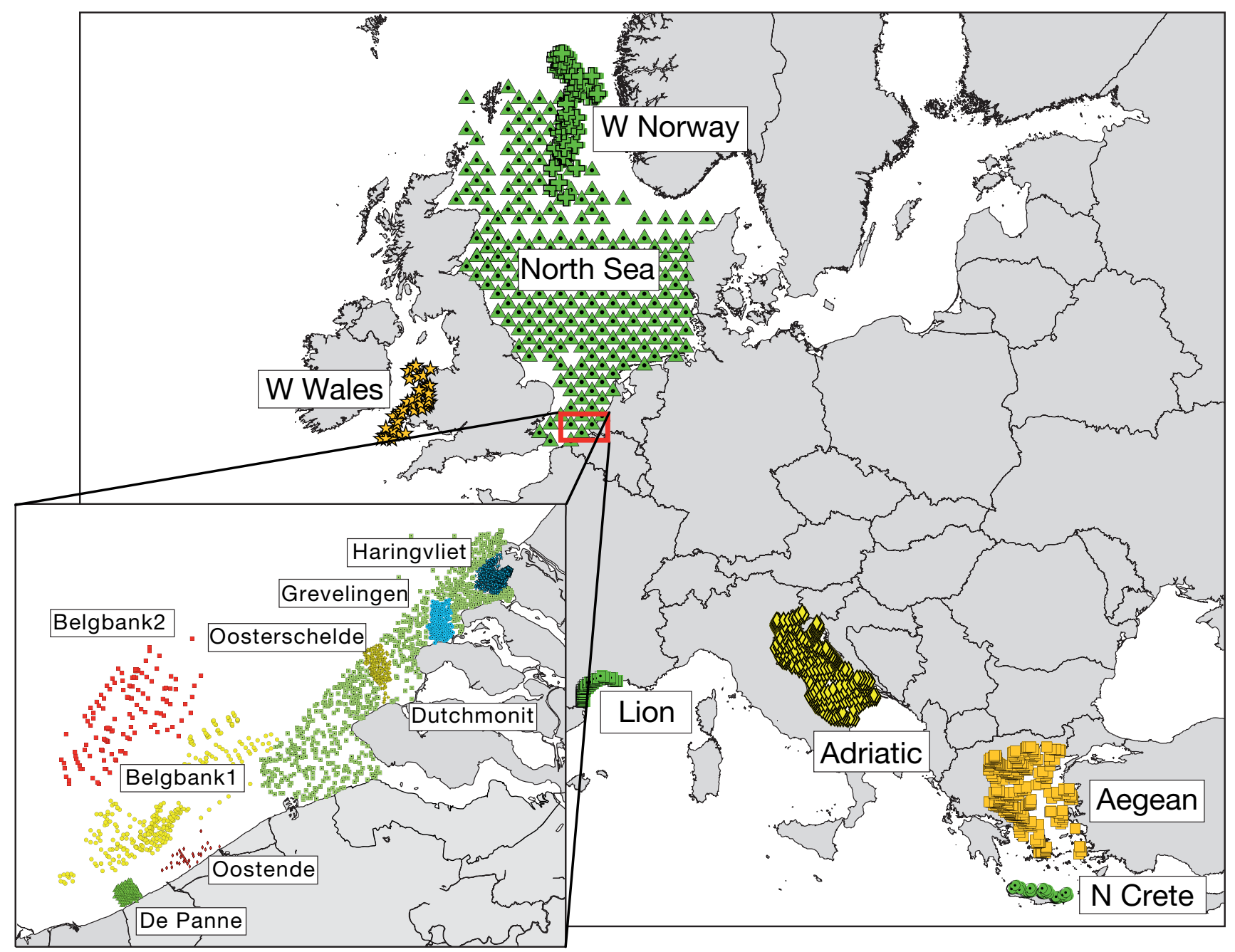

Fig. 1. Geographic groups selected for the present study $(n=15)$

of increase of species richness with increasing sampling area and $c$ is the species richness for the elemental unit of area (Rosenzweig 1995). According to Gray's (2000) terminology on scales of diversity, and depending upon the extent of the surveyed area, $S$ represents $\mathrm{SR}_{\mathrm{S}}$, the sample species richness, or the species richness of a number of sampling units from a site of defined area. Following the same terminology, $c$ can be interpreted as $S_{R}$, the point species richness, and $z$ as a measure of the $\beta$ diversity as defined by MacArthur \& Wilson (1967).

Additional environmental data. Besides depth, which is available for most individual records in the data set, and the surveyed surface that was estimated with elementary GIS techniques, data on net primary production ( $\mathrm{gC}$ $\mathrm{m}^{-2} \mathrm{mo}^{-1}$ ) at the scale of the geographic groups were downloaded from the Environmental Marine Information System (EMIS) website (http://emis.jrc.ec.europa. eu). These data are derived from satellite remote sensing of ocean color for the years 2000 to 2004 and the primary production calculation itself is based on the formulation obtained through dimensional analysis by Platt \& Sathyendranath (1993). The assignment of the photosynthetic parameters $P^{\mathrm{B}}{ }_{\max }$ and $\mathrm{E}_{\mathrm{k}}$ is achieved by the combined use of a temperature-dependent relationship for the maximum growth rate (Eppley 1972) and the use of variable formulation to retrieve the carbon:chlorophyll ratio following the empirical relationship of Cloern et al. (1995). In order to account for the diminution of the downwards flux of primary production as a function of depth, the estimates of primary production obtained from EMIS were corrected with a semi-empirical model for the depth dependence of remineralization rate as proposed by Andersson et al. (2004):

$$
F_{\mathrm{Z}}=F_{0}\left[(1-p) \mathrm{e}^{-b 1 z}+p \mathrm{e}^{-b 2 z}\right]
$$

with $F_{z}$ the flux of remineralization at depth $z, F_{0}$ the flux at the surface and fitted parameters $p(0.17), b_{1}$ $(0.018)$ and $b_{2}(0.00046)$. Metadata information is provided in Table 1. 


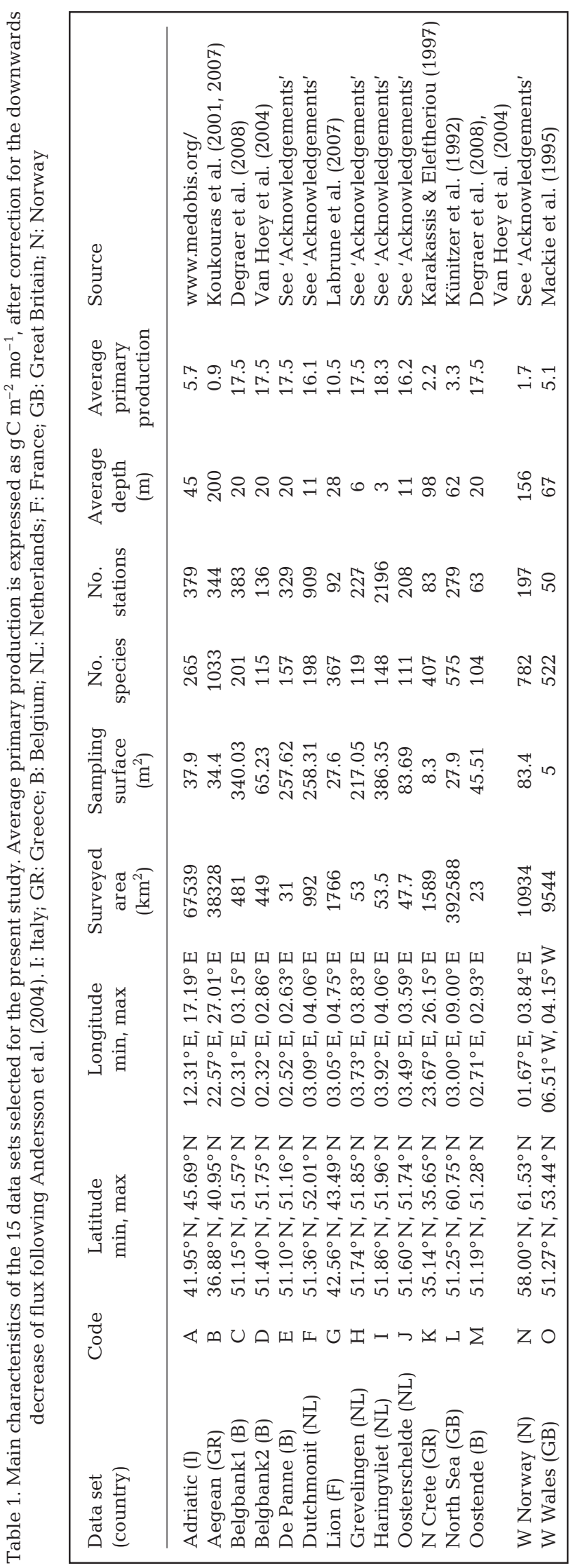

\section{RESULTS}

\section{Species accumulation curve: gridded approach}

Fig. 2 shows, for each of the 15 data sets, the number of species observed within the grid cells of the gridded approach versus the average area sampled $\left(\mathrm{m}^{2}\right.$ per grid cell). The Arrhenius plot model (Eq. 1) fits very well to the data with average $c$-values of $1.56 \pm 0.25$ and average $z$-values of $0.51 \pm 0.05$ for an average $r^{2}=$ 0.99 (Table 2). Due to interdependence between the observed numbers of species at the different scales, we refrained from providing significance levels to the regressions and formal intergroup comparisons.

The values of the species accumulation curve intercept (c) show a clear geographical dependency (Fig. 3). The 8 data sets from the Dutch and Belgian shallow waters are characterized by low $c$-values with an average of $14.3 \pm 0.9$ as expressed in number of species (after log inverse transformation of the intercept values). The remaining 7 data sets (Mediterranean, North Sea and North Atlantic) show considerably higher $c$-values with an average of $102.8 \pm 1.4$ species.

The slopes of the species accumulation curves show much less variability. In contrast to the intercepts, the slopes of the species accumulation curves showed almost no variability. When the value of the intercepts (no. of species $\mathrm{m}^{-2}$ ) for each accumulation curve was substracted from the number of species values, all the curves overlapped (see Fig. 4). The intercept-corrected numbers of species (log) show a strong relation with the log of the sampled area (Fig. $4, r^{2}=0.94$ ). The value

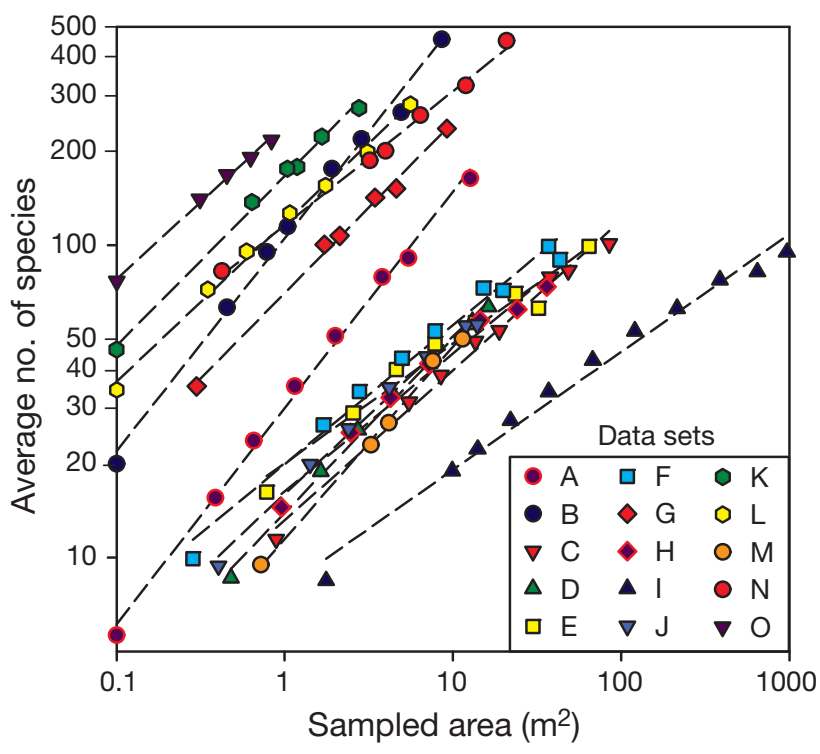

Fig. 2. Species accumulation curves (Eq. 1) fitted for each data set between the average number of species and corresponding average sampling areas at the different spatial scales (gridded approach). Data set codes are listed in Table 1 
Table 2. Parameter values of the species accumulation curves (Eq. 1) fitted for each geographical group following the gridded approach. $z$ : rate of increase of species richness with increasing sampling area; $C$ : species richness for the elemental unit of area. The number of observations (N) and the corresponding $\mathrm{R}^{2}$ are also indicated

\begin{tabular}{|lccccc|}
\hline Data set & Code & $C$ & $Z$ & $\mathrm{~N}$ & $\mathrm{R}^{2}$ \\
\hline Adriatic & $\mathrm{A}$ & 1.478 & 0.692 & 8 & 0.996 \\
Aegean & $\mathrm{B}$ & 2.021 & 0.681 & 8 & 0.992 \\
Belgbank1 & $\mathrm{C}$ & 1.119 & 0.480 & 8 & 0.990 \\
Belgbank2 & $\mathrm{D}$ & 1.141 & 0.560 & 7 & 0.994 \\
De Panne & $\mathrm{E}$ & 1.300 & 0.383 & 8 & 0.961 \\
Dutchmonit & $\mathrm{F}$ & 1.299 & 0.444 & 9 & 0.982 \\
Lion & $\mathrm{G}$ & 1.846 & 0.548 & 6 & 0.994 \\
Grevelingen & $\mathrm{H}$ & 1.211 & 0.441 & 7 & 0.979 \\
Haringvliet & $\mathrm{I}$ & 0.904 & 0.377 & 11 & 0.984 \\
Oosterschelde & $\mathrm{J}$ & 1.203 & 0.505 & 7 & 0.990 \\
North Crete & $\mathrm{K}$ & 2.220 & 0.543 & 6 & 0.995 \\
North Sea & $\mathrm{L}$ & 2.071 & 0.509 & 7 & 0.995 \\
Oostende & $\mathrm{M}$ & 1.058 & 0.617 & 5 & 0.995 \\
W Norway & $\mathrm{N}$ & 2.064 & 0.429 & 6 & 0.994 \\
W Wales & $\mathrm{O}$ & 2.384 & 0.493 & 5 & 0.996 \\
\hline
\end{tabular}

for the $z$-parameter calculated for the whole data set after the intercept correction is estimated as 0.44 , corresponding with a 3 -fold increase of the number of species when the sampling surface increases by 1 order of magnitude $\left(S \approx A^{0.44}\right)$. The homogeneity of slopes among the different geographic groups reflects the similar increase in species richness as function of the sampling area in the different datasets.

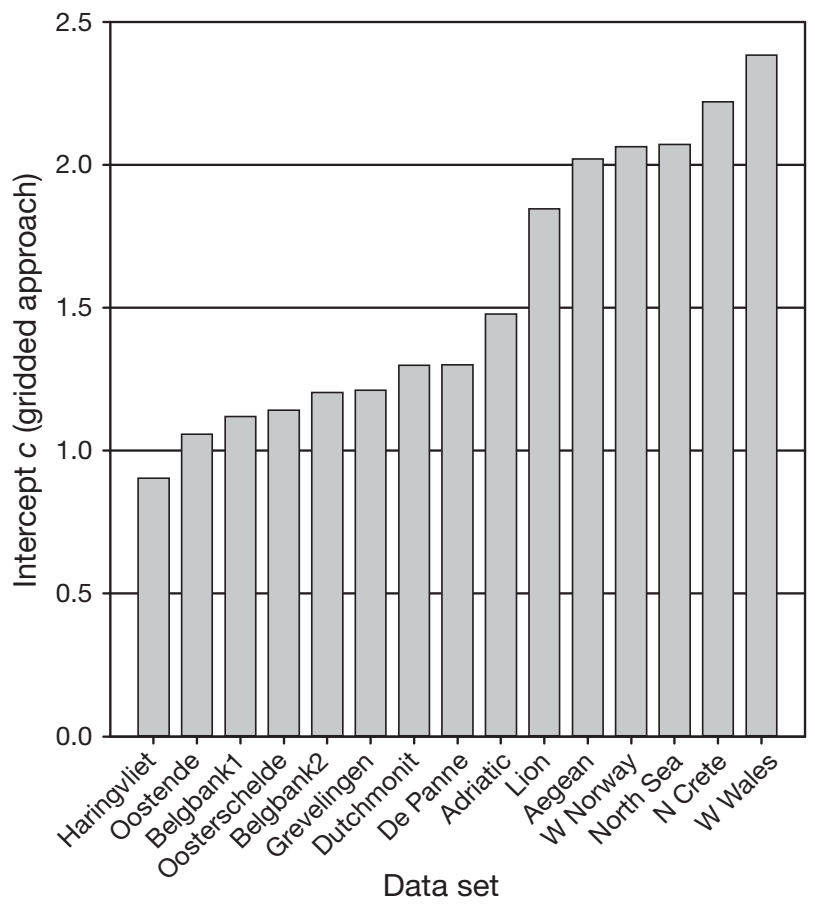

Fig. 3. Intercepts $\left(c, \log \left[\right.\right.$ no. of species $\left.\left.\mathrm{m}^{-2}\right]\right)$ of the species accumulation curves (See Fig. 1) fitted for each geographical group and sorted by increasing values

\section{Species accumulation curves: randomization approach}

The species accumulation curves obtained by randomly assembled samples from the entire dataset (Fig. 5) show distinctive curvilinearity. In particular, the groups assembled from only a few original samples have fewer species than would be expected on the basis of extrapolation from the larger assembled groups.

The values of the slope, however, did not vary much among the data sets $(0.41 \pm 0.05)$ and showed a very strong relationship (Fig. 6) with the slopes obtained with the gridded approach $\left(z_{\mathrm{rand}}=1.01 \times z_{\mathrm{avg}}-0.11\right.$, $\left.r^{2}=0.92\right)$. The intercepts obtained with the randomization approach were also very closely related to the values obtained with the gridded approach $\left(C_{\text {rand }}=2.61 \times\right.$ $C_{\text {grid }}{ }^{0.88}, \mathrm{r}^{2}=0.95$ )

\section{Relating species richness to the environment}

A corollary of the homogeneity of slopes of the species accumulation curves among the selected data sets is that most of the variation in the number of species observed in the database is accounted for by the intercept of this relation. The value taken by the intercept can therefore be considered as a measure of intrinsic species richness of the fauna sampled in the different data sets. The distribution of these values was com-

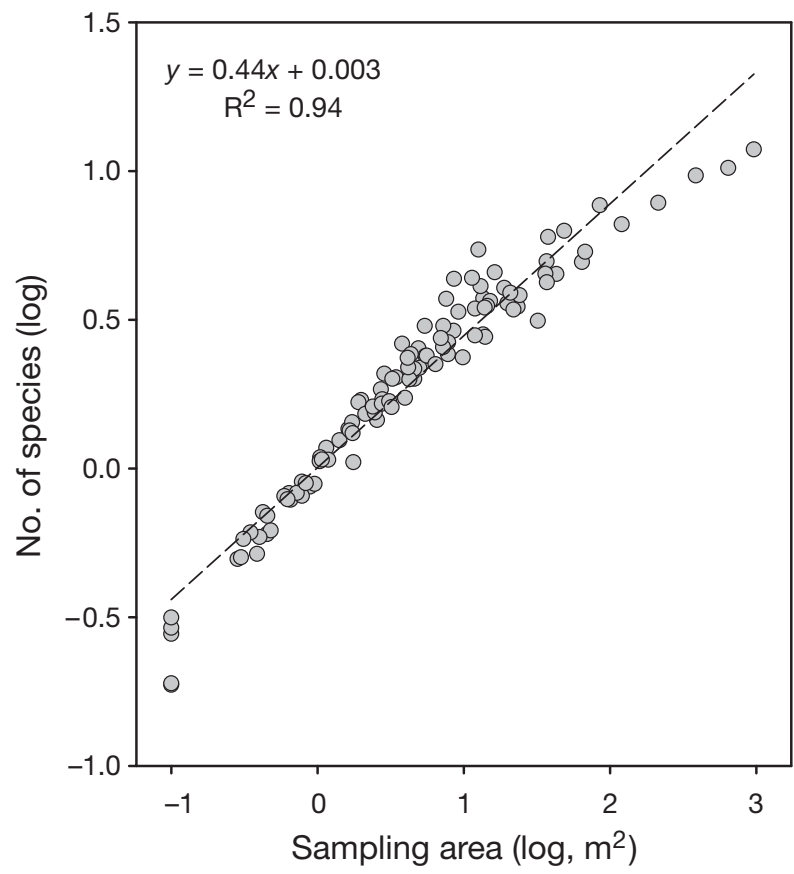

Fig. 4. Pooled regression of the average number of species (log) corrected for the intercepts of the species accumulation curves (see Fig. 1) as function of the average sampling areas (log) at the different spatial scales (gridded approach) 


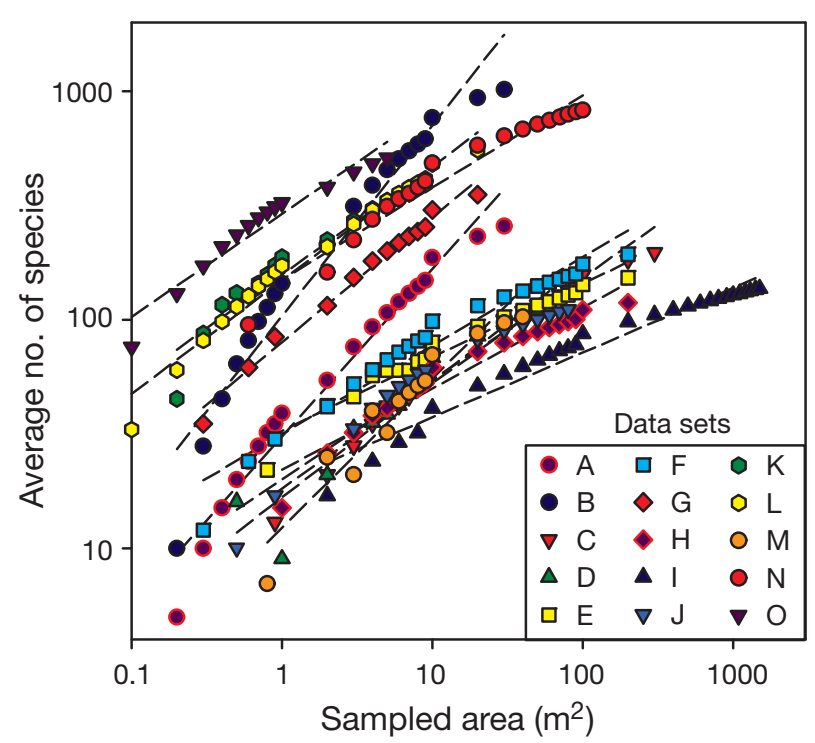

Fig. 5. Species accumulation curves (Eq. 1) fitted for each dataset between the average number of species and the average sampling areas obtained by randomized accumulation of the individual grid cells over the whole surveyed area (randomization approach)

pared with that of the factors retained in the prevailing hypotheses for the determination of species richness: surveyed area, latitude, depth and productivity. Whereas no relationship was found between the intercepts calculated for the 15 geographic groups and their average latitude $\left(r^{2}=0.07\right)$, significant relationships $\left(\mathrm{r}^{2}>0.50\right)$ were found with the surveyed area, depth and productivity (Fig. 7A-C). However, these 3 explaining factors show strong interrelationships (Fig. 7D) as small (area) monitoring surveys are generally designed in shallow, productive, coastal waters whereas extended surveys are mostly preferred in deep, oligotrophic, offshore areas. Among the 3 explaining factors that were tested here, the highest coefficient of determination was found for productivity $\left(r^{2}=0.83\right)$.

\section{DISCUSSION}

\section{Species-area relationship versus species accumulation}

In the gridded approach, where species were accumulated in samples collected over increasing surface area (grids containing on average 1, 2, 4 ... 1024 sampling locations), the species accumulation curve accounts for the numbers of species found in increasingly larger areas. As a result of the linear increase of the sampling surface with the surface of the grid cells, the accumulation curve between the number of species and the sampling surface is homologous to a species-

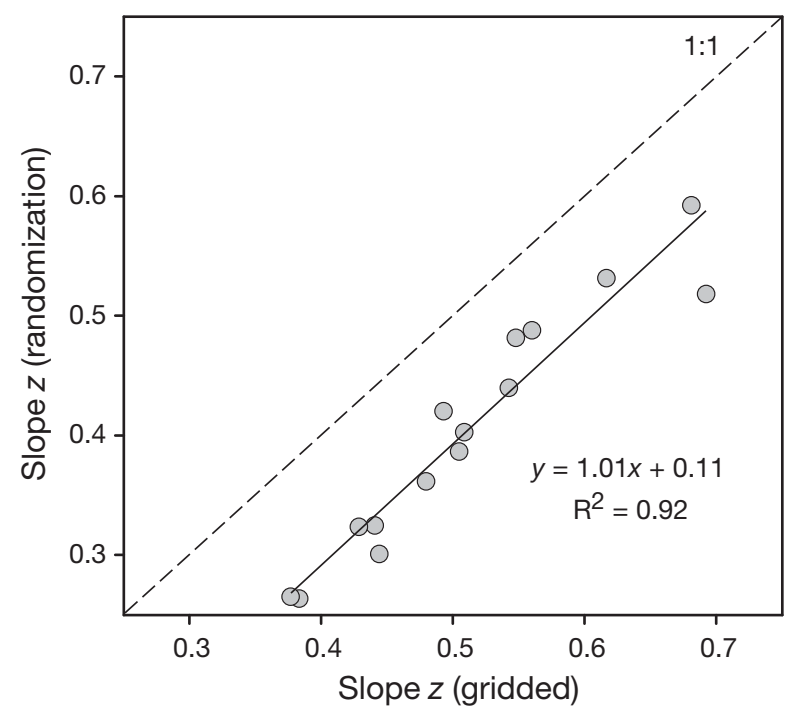

Fig. 6. Relationship between the slopes $(z)$ of the species accumulation curves obtained with the 2 methods: randomization vs. the gridded approach

area relationship. In the randomization approach, where samples were randomly selected over the whole survey area, the numbers of species found at increasing sampling surface area typically represent a species accumulation curve.

Ugland et al. (2003) warned against the confusion between species accumulation curves and speciesarea relationships, as the former measures the rate of accumulation of different species as the area sampled is increased and the latter describes how the number of species varies with the size of the surveyed area (Gray et al. 2004a,b). Furthermore, the data analysis by Ugland et al. (2003) showed intrinsic differences in the formulation of both relationships as the species accumulation follows a semi-log increase, whereas the species-area relationship is log-log.

We have applied both models (log-log and semi-log) to our data in order to compare their suitability for describing both the grid and random approaches. The quality of fit in all cases is quite high, with average $\mathrm{r}^{2}$ values all >0.93. However, both models showed systematic error patterns respective to the true data, with concave and convex distribution of the residuals against the sampling area when fitting with the semi$\log$ and the $\log$-log functions, respectively.

As expected, the semi-log function produces a better fit than the $\log -\log$ function in the randomization approach, with average $r^{2}$ values reaching 0.99 and 0.96, respectively. Conversely, the fit was lower with the semi-log $\left(r^{2}=0.93\right)$ than with the $\log -\log$ function $\left(\mathrm{r}^{2}=0.99\right)$ in the gridded approach. Given both models showed conceptual discrepancies with the true data as evidenced from the systematic error patterns, 

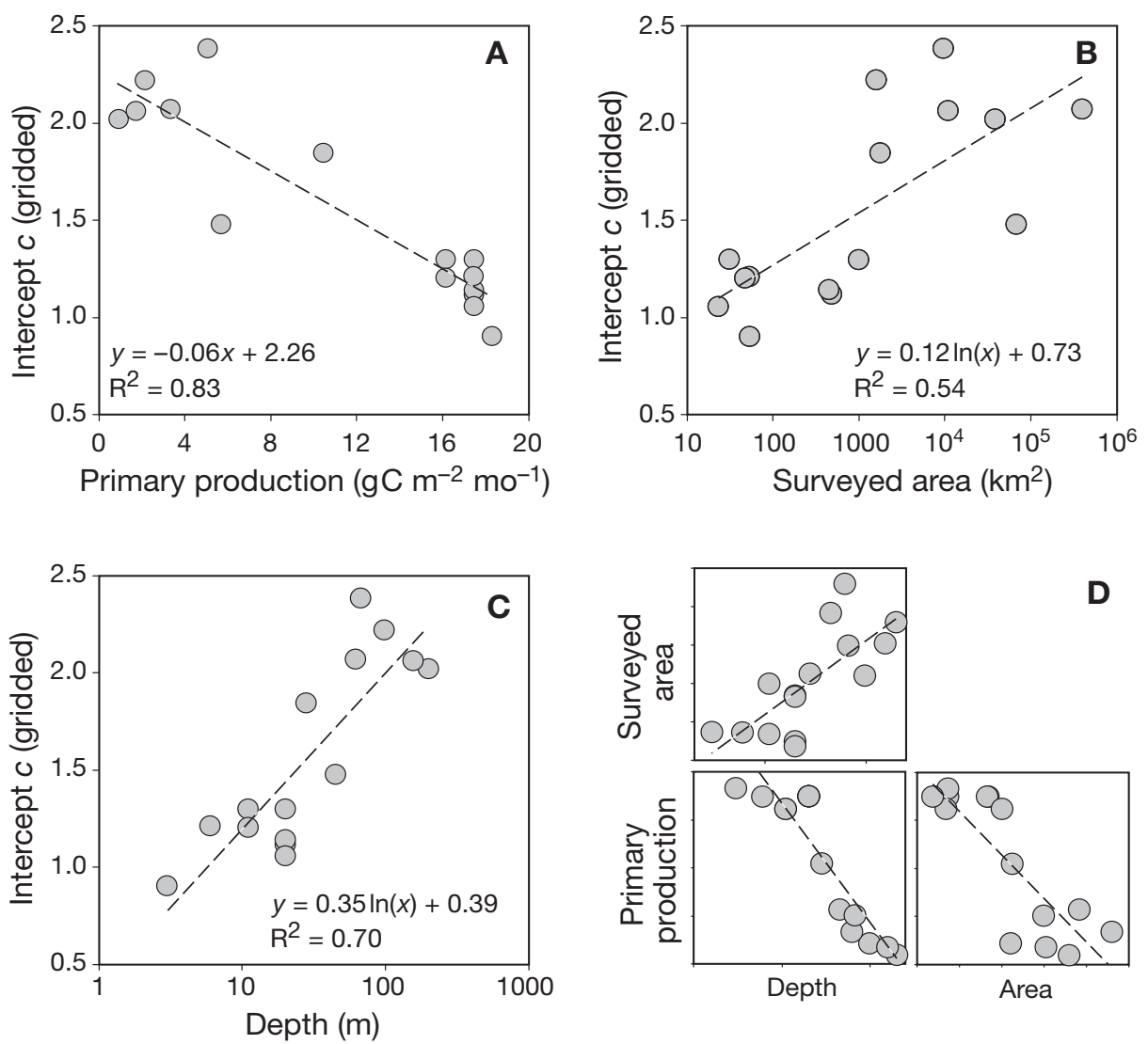

Fig. 7. Intercept $(c)$ of the species accumulation curves (gridded approach, see Fig. 1) as a function of the average values of $(\mathrm{A})$ primary production, (B) surveyed area and (C) depth, and (D) relationships between these explaining factors

there is no clear argument to choose one model over another in our comparison between the different approaches. As a single model has to be employed to allow direct comparisons between the parameters fitted with our 2 approaches, the log-log model was chosen given it produced a slightly better fit than the semi-log model.

The comparison between the 2 approaches shows that the randomization method includes the total geographic variation in habitats into the estimates of number of species for groups with a certain sampling surface. This inclusion is incomplete in the smallest groups, but reasonably consistent from approximately 10 samples and above (Fig. 5). In the gridded approach, more heterogeneity in habitat is added as the sampled surface increases, since this corresponds to larger and larger grid cells. Consequently, the slopes of the Arrhenius plots in the gridded approach are systematically higher than those in the randomization approach. Intercepts in the randomization approach are also estimated as higher values than in the gridded approach, because the randomization procedure projects some of the large-scale geographical variation down to the smallest scale.

Despite these differences, however, the estimates of the intercepts in both methods are very highly correlated to one another. The intercepts represent number of species expected at the unit sample area, and can be considered as an adequate biodiversity indicator of the fauna sampled. The correlation between these intercepts and environmental values that can serve as an explanatory factor for biodiversity is warranted, since the result appears to be relatively independent of the method used to estimate the intercepts.

\section{Species richness and the environment}

Exploring causality in the observed patterns remains a risky task since the associated environmental variables are closely interrelated (Fig. 7). In addition, the present study does not consider the many other factors which likely control the species richness, such as habitat boundaries (Gray 2000), rarity vs. dominance (Gray et al. 2005), historical constraints (Gray 2001) and, at a smaller scale, the influence of the physical variables such as temperature, salinity and hydrodynamics. Nevertheless, the spatiotemporal scales at which the variables (biotic and abiotic) are considered in the present study are larger than the range of action of the previously mentioned control factors, the effects of which are leveled off at the present observation scale.

Therefore, further reflection on the present observations and additional data analysis might help at 
improving our insight into the processes controlling marine benthic macrofaunal biodiversity.

\section{Depth}

Among the 3 factors found to be associated with diversity levels (depth, area and productivity), depth is the most controversially linked to biodiversity. Sanders (1968) attempted to explain the increase in diversity with depth from coastal areas to $2000 \mathrm{~m}$ (his deepest observations) with his stability-time hypothesis. This hypothesis states that the species richness of shallow areas is physically controlled, whereas it becomes biologically accommodated in the deep sea. The mechanism suggested is that competitive interactions over evolutionary time in the stable environment of the deep sea have led to a large number of specialized species within narrow niches. Peters (1976) pointed at the tautological nature of this hypothesis, as complex competitive interactions can be considered as both the cause and the result of the presence of a large number of specialized species. Furthermore, it is worth observing that the data set studied by Sanders (1968) only contains 37 samples, only 4 of which are from the deep sea, a singularly small number when compared with the general scope of the hypothesis (Abele \& Walters 1979). Abele \& Walters (1979) (re)evaluated the data used by Sanders (1968) and showed clear flaws in the data, such as heterogeneous sampling techniques, arbitrary taxonomic (polychaete-bivalve fraction) selection of data and heterogeneous habitat origin of samples. Finally, Gray (2001) (re)examined the depth (stability-time) hypothesis, showed that it was falsified in most available data sets and concluded that no clear trend in increasing species was observed from coasts to the deep sea. Abele \& Walters (1979) also showed that the observed coast-deep sea gradient in (polychaete) species richness could be satisfactorily associated $(99 \%)$ with the species-area relationship, as larger domains were generally surveyed in the deep sea than in coastal areas. The data from the present study show the same pattern, with a strong relationship between average depth and the surveyed area of the data sets, a finding which might be indicative of a coincidental relationship between depth and species richness.

\section{Surveyed area}

Gray (2001) verified the validity of the species-area curve (Arrhenius curve) on a data set from the benthos of the Norwegian continental shelf, and concluded that such a general rule that has been mostly observed in terrestrial systems was also due to apply to the marine environment. However, total survey area as an explanatory variable is unsatisfactory from an ecological point of view, as it basically depends on the configuration of the sampling designs which are characterized by larger areas covered in deep waters than in coastal areas.

Our different approaches to the species accumulation curves only partly compensate for this artefact. The gridding method uses smaller geographic grid cells in the data sets with smaller total area surveyed. Therefore, samples that are found together in a grid of sufficient size to harbour, say, 4 samples, are geographically closer together in the data sets with a small total area surveyed than in the data sets with a larger area. Thus, if geographical distance was the major factor determining the similarity between a pair of samples, it would be possible that this spatial autocorrelation interferes with our analysis. There are 2 reasons why this seems unlikely. The first is that total area surveyed correlates with the intercepts of the species accumulation curves (in the gridded approach) and not with the slopes. If the increase of the intersample distance controlled the number of species found in a grid, the number of species should grow faster with grid size in the data sets with a large surveyed area. Consequently, the size of the total area would correlate with the slopes and not with the intercepts, as in the present case. The second reason is that the slopes determined in the 2 methods are highly correlated. The randomization approach always samples from the entire geographical range. Except for the lowermost samples, where this sampling is incomplete, one would not expect that enlargement of the geographical range sampled has a strong influence on the slopes in the randomization approach. Consequently, since the slopes in the gridded approach are correlated to those from the randomization approach, it seems unlikely that the former are dominated by the range extension effect. Finally, we note that the intercepts between both approaches are highly correlated. Intercepts of the randomization approach are expected to reflect effects of the geographical range surveyed, since this method extrapolates the variability in habitats down to the lowest scale. In accordance with this hypothesis, we do find larger intercepts in this approach. Again, however, the effect does not override the influence of differences in point species richness that appear to be present in the data sets. We therefore conclude that the differences in intercepts primarily reflect real differences in point species richness, and that the correlation between these intercepts and total area surveyed is a coincidental consequence of the configuration of the sampling designs that are characterized by larger areas covered in deep waters than in coastal areas. 

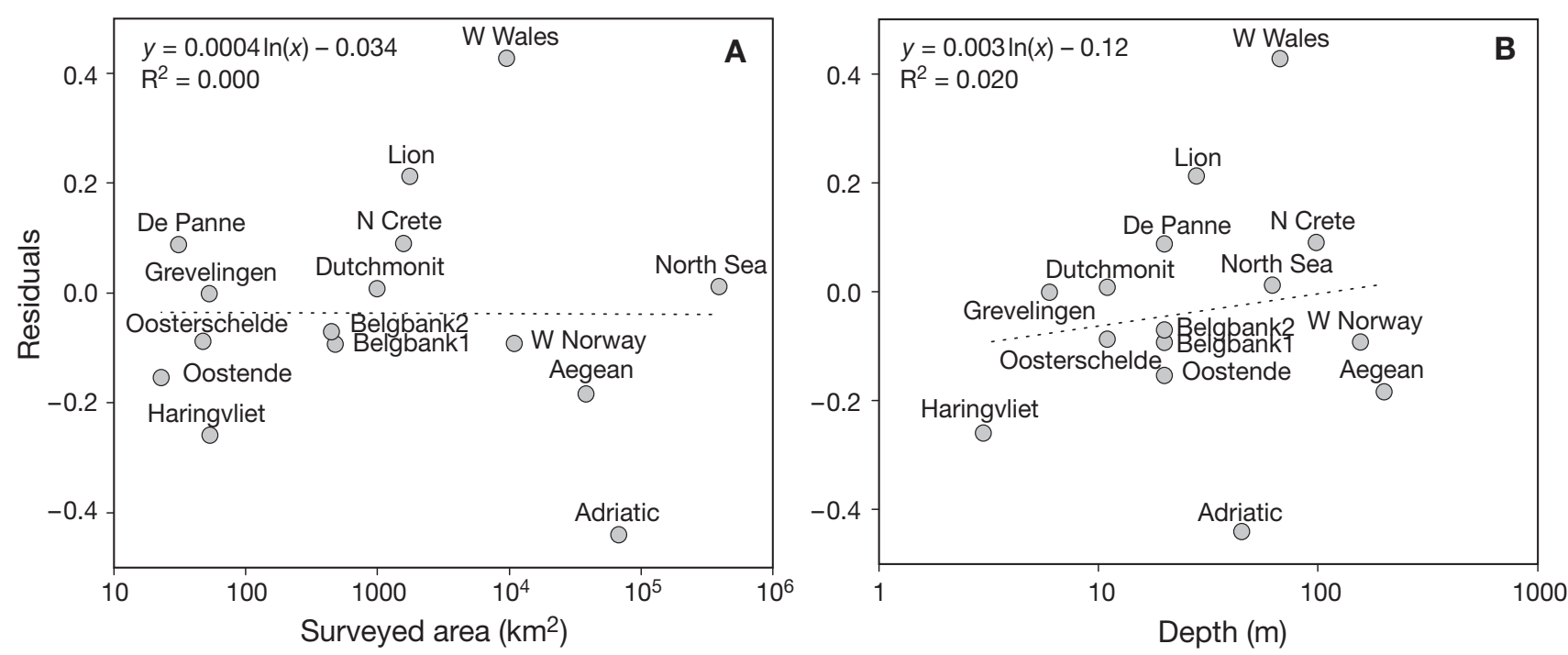

Fig. 8. Residuals from the regression of the species accumulation curve intercepts $(\mathrm{C})$ on primary production (see Fig. 7A) as a function of (A) surveyed area and (B) depth

Productivity

Both data sets used to investigate the D-P relationship (macrofauna and productivity) are characterized by their high level of spatiotemporal integration (average values over whole study areas). This inaccuracy is advantageously compensated by the robustness of the averaged data where local heterogeneities due, for example, to advective transports, might have blurred the signals when considered at the scale of the individual samples. The present data showed a strong negative relationship between the intercept of the species richness (point species richness) and the fraction of primary productivity reaching the bottom. This relation might correspond with the decreasing part of the unimodal D-P curve. Smith (2007) compiled a large number of studies confirming the prevalence of hump-shaped distributions of species richness against system productivity. In cases where monotonic (negative/positive) trends were found, it was suggested that a wider range (often $\geq 2$ orders of magnitude) of productivities would have been necessary to reveal the entirety of a humped D-P curve. This might be the case in the present study, where no data were available from regions with average productivity levels lower than about $1 \mathrm{~g} \mathrm{C} \mathrm{m}^{-2} \mathrm{mo}^{-1}$. It is indeed likely that an increase in species diversity with increasing resource supply should be observed in very unproductive conditions due to minimum resource requirements. After all, one can be sure that the origin lies on the curve: no animal could survive when resources are nil. If such a situation occurred within the present data set, the resolution used for both the benthos and the production data (average over study areas) would not have allowed us to isolate it.
Levin et al. (2001) describe a deep-sea data set where diversity of nematodes increases with organic flux. The range of flux is 2 orders of magnitude lower than the range described in the present study. Thus, it is very likely that this increasing trend of diversity with productivity can present the ascending part of what is, essentially, a humped curve.

Residual analysis of the relationship with productivity is an interesting way to study the importance of the other factors, depth and surveyed area. As stressed in Fig. 8, the residuals of this regression show no relationship at all with surveyed area or depth. Conversely, a significant relationship was found between the residuals of intercepts on depth or surveyed area and productivity.

When the intercepts of the species-area relationship are plotted against the values of primary production measured at sea surface, the regression coefficient equals 0.68 , compared with the value of 0.83 that is obtained when primary production is corrected for the depth dependence of organic flux to the sediment. After the correction for depth, the average ratio between the levels of carbon enrichment and the surface levels of primary production was about $80 \%$ in the 8 data sets from the Dutch and Belgian shallow waters, whereas it was about one-third in the remaining 7 data sets (Mediterranean, North Sea and North Atlantic). The present data suggests that the strong control of the bottom enrichment by depth might account for the effect of depth on species richness.

Acknowledgements. The authors thank MarBEF, the EU funded Network of Excellence on the Marine Biodiversity and Ecosystem Functioning and most especially the Theme 1 
(large-scale, long-term biodiversity patterns over the European seas) initiative for data collection. Within this framework, C. Arvanitidis played an essential role with the organization of a successful workshop hosted by the Institute of Marine Biology and Genetics (HCMR-Crete). The achievement of this study was tremendously facilitated with the efficient work by the members of the VLIZ: W. Appeltans, S. Claus and E. Vanden Berghe, who were responsible for the integration of the data sets within 1 relational database. Thanks are also due to A. Rose (Senckenberg Research Institute) for his active contribution to the discussion at the start of this project. This study is the result of a cooperative work between the primary authors and several data providers who were also involved in the finalization of the paper. Grateful acknowledgements are due to all data providers: Aegean Sea (A. Koukouras, University of Thessaloniki), Belgbank1/ Belgbank2/De Panne/Oostende (S. Degraer, M. Vincx, W. Willems, G. Van Hoey, J. Speybroeck, Ghent University), Dutchmonit/Grevelingen/Haringvliet/Oosterschelde (H. Hummel, W. C. H. Sistermans, CEME), Lion (J. M. Amouroux, A. Grémare, C. Labrune), N Crete (I. Karakassis), North Sea (J. A. Craeymeersch, IMARES; G. Duineveld, NIOZ; C. Heip; P. Kingston, Heriot-Watt University; E. Rachor, AWI; E. Vanden Berghe, VLIZ), W Norway (The Norwegian Oil Industry Association, Akvaplan-niva, Det Norske Veritas), W Wales (A. S. Y. Mackie; P. G. Oliver, National Museum Wales; E. I. S. Rees, University of Bangor). V.E. received financial support from MarBEF (GOCE-CT-2003-505446). This is publication 4497 of the Netherlands Institute of Ecology (NIOO-KNAW), Monitor Taskforce Publication Series 2009-02.

\section{LITERATURE CITED}

Abele LG, Walters K (1979) Stability-time hypothesis: reevaluation of the data. Am Nat 114:559-568

Andersson JH, Wijsman JWM, Herman PMJ, Middelburg JJ, Soetaert K, Heip C (2004) Respiration patterns in the deep ocean. Geophys Res Lett 31:L03304, doi: 10.1029/2003GL 018756

Cloern JE, Grenz C, Vidergar-Lucas L (1995) An empirical model of the phytoplankton chlorophyll:carbon ratio-the conversion factor between productivity and growth rate. Limnol Oceanogr 40:1313-1321

Connell JH, Orias E (1964) The ecological regulation of species diversity. Am Nat 98:399-414

> Degraer S, Verfaillie E, Willems W, Adriaens E, Vincx M, Van Lancker V (2008) Habitat suitability modelling as a mapping tool for macrobenthic communities: an example from the Belgian part of the North Sea. Cont Shelf Res 28: 369-379

Eppley RW (1972) Temperature and phytoplankton growth in the sea. Fish Bull 70:1063-1085

- Gray JS (1997) Marine biodiversity: patterns, threats and conservation needs. Biodivers Conserv 6:153-175

> Gray JS (2000) The measurement of marine species diversity, with an application to the benthic fauna of the Norwegian continental shelf. J Exp Mar Biol Ecol 250:23-49

Gray JS (2001) Marine diversity: the paradigms in patterns of species richness examined. Sci Mar 65:41-56

Gray JS (2002) Species richness of marine soft sediments. Mar Ecol Prog Ser 244:285-297

- Gray JS, Poore GCB, Ugland KI, Wilson RS, Olsgard F, Johannessen $\varnothing$ (1997) Coastal and deep-sea benthic diversities compared. Mar Ecol Prog Ser 159:97-103

Gray JS, Ugland KI, Lambshead J (2004a) Species accumulation and species area curves: a comment on Scheiner (2003). Glob Ecol Biogeogr 13:473-476
Gray JS, Ugland KI, Lambshead J (2004b) On species accumulation and species-area curves. Glob Ecol Biogeogr 13: $567-568$

> Gray JS, Bjørgesæeter A, Ugland KI (2005) The impact of rare species on natural assemblages. J Anim Ecol 74: 1131-1139

> Gross K, Cardinale BJ (2007) Does species richness drive community production or vice versa? Reconciling historical and contemporary paradigms in competitive communities. Am Nat 170:207-220

> Hall SJ, Gray SA, Hammett ZL (2000) Biodiversity-productivity relations: an experimental evaluation of mechanisms. Oecologia 122:545-555

- Karakassis I, Eleftheriou A (1997) The continental shelf of Crete: structure of macrobenthic communities. Mar Ecol Prog Ser 160:185-196

Koukouras A, Voultsiadou E, Kitsos MS, Doulgeraki S (2001) Macrobenthic fauna diversity in the Aegean Sea, affinities with other Mediterranean regions and the Black Sea. Bios 6:61-76

Koukouras A, Sinis AI, Bobori D, Kazantzidis S, Kitsos MS (2007) The echinoderm (Deuterostomia) fauna of the Aegean Sea, and comparison with those of the neighbouring seas. J Biol Res 7:67-92

> Künitzer A, Basford D, Craeymeersch JA, Dewarumez JM and others (1992) The benthic infauna of the North Sea: species distribution and assemblages. ICES J Mar Sci 49: 127-143

> Labrune C, Grémare A, Amouroux JM, Sarda R, Gil J, Taboada S (2007) Assessment of soft-bottom polychaete assemblages in the Gulf of Lions (NW Mediterranean) based on a mesoscale survey. Estuar Coast Shelf Sci 71: 133-147

Leibold MA (1999) Biodiversity and nutrient enrichment in pond plankton communities. Evol Ecol Res 1:73-95

Levin LA, Etter RJ, Rex MA, Gooday AJ and others (2001) Environmental influences on regional deep-sea species diversity. Annu Rev Ecol Syst 32:51-93

Levinton JS (1995) Marine biology: function, biodiversity, ecology. Oxford University Press, New York

MacArthur RH, Wilson EO (1967) The theory of island biogeography. Princeton University Press, Princeton

Mackie ASY, Oliver PG, Rees EIS (1995). Benthic biodiversity in the Southern Irish Sea. Studies in marine biodiversity and systematics from the National Museum of Wales. BIOMÔR Report 1, National Museums \& Galleries of Wales, Cardiff

> Peters RH (1976) Tautology in evolution and ecology. Am Nat 110:1-12

> Platt T, Sathyendranath S (1993) Estimators of primary production for interpretation of remotely-sensed data on ocean color. J Geophys Res C 98:14561-14576

Rex MA (1981) Community structure in the deep-sea benthos. Annu Rev Ecol Syst 12:331-353

Rex MA, Etter RJ (1998) Bathymetric patterns of body size: implications for deep-sea biodiversity. Deep-Sea Res II 45: 103-127

Rosenzweig ML (1971) Paradox of enrichment: destabilization of exploitation ecosystems in ecological time. Science 171: 385-387

> Rosenzweig ML (1992) Species diversity gradients: we know more and less than we thought. J Mammal 73:715-730

Rosenzweig ML (1995) Species diversity in space and time. Cambridge University Press, Cambridge

Rosenzweig ML, Abramsky ZN (1993) How are diversity and productivity related? In: Ricklefs RE, Schluter D (eds) Species diversity in ecological communities: historical and 
geographical perspectives. University of Chicago Press, Chicago

Sanders HL (1968) Marine benthic diversity: a comparative study. Am Nat 102:243

Smith VH (2007) Microbial diversity-productivity relationships in aquatic ecosystems. FEMS Microbiol Ecol 62:181-186

Tilman D, Pacala S (1993) The maintenance of species richness in plant communities. In: Ricklefs RE, Schluter D (eds) Species diversity in ecological communities: historical and geographical perspectives. University of Chicago Press, Chicago

Ugland KI, Gray JS, Ellingsen KE (2003) The species-accu-

Submitted: June 5, 2008; Accepted: March 11, 2009 mulation curve and estimation of species richness. J Anim Ecol 72:888-897

Vanden Berghe E, Claus S, Appeltans W, Faulwetter S and others (2009) MacroBen integrated database on benthic invertebrates of European continental shelves: a tool for large-scale analysis across Europe. Mar Ecol Prog Ser 382: $225-238$

Van Hoey G, Degraer S, Vincx M (2004) Macrobenthic communities of soft-bottom sediments at the Belgian Continental Shelf. Estuar Coast Shelf Sci 59:601-615

> Wright DH (1983) Species-energy theory: an extension of species-area theory. Oikos 41:496-506

Proofs received from author(s): April 27, 2009 